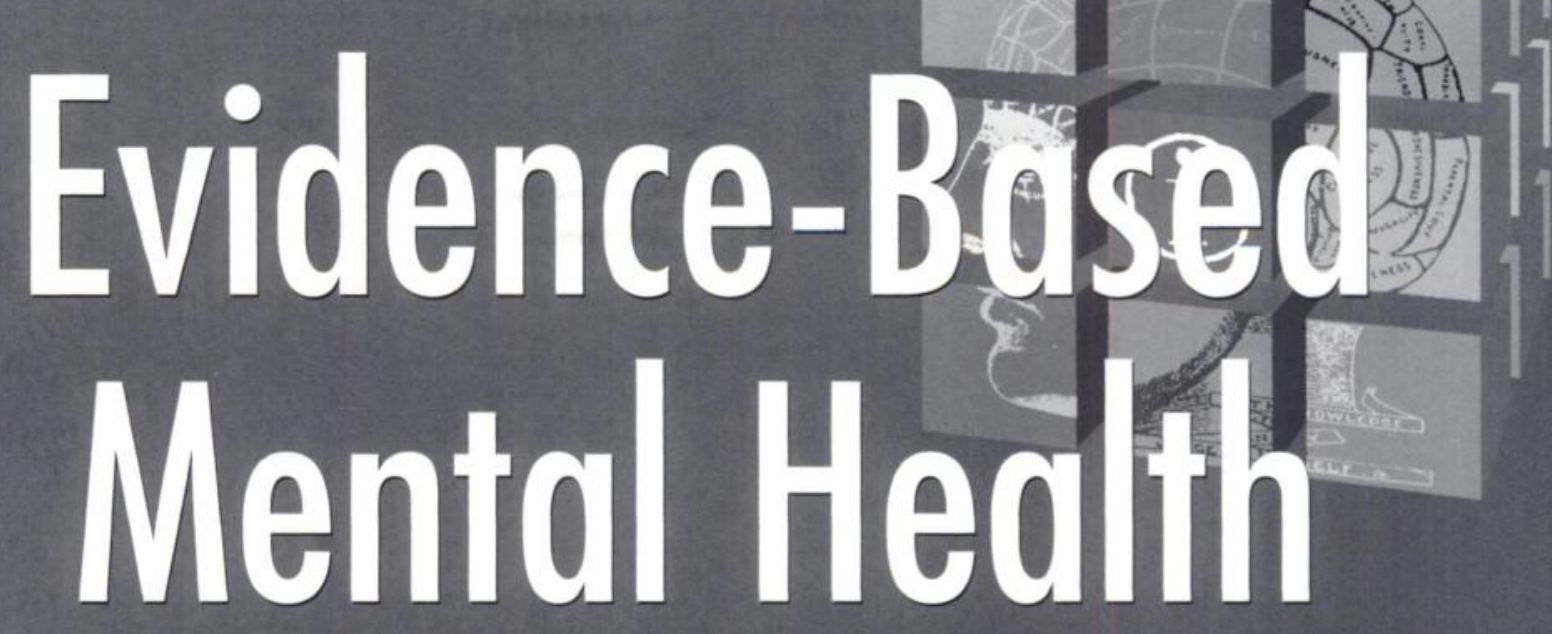

EDITORS: John Geddes, Shirley Reynolds, David Streiner \& Peter Szatmari

ental health practitioners can now stay up-to-date with the best available
evidence - as it is published.

New from the BMJ Publishing group, 'Evidence-Based Mental Health' follows on from the success of its sister publication 'Evidence-Based Medicine' and is designed to meet the needs of mental health specialists worldwide. The first issue will be published in February 1998.

Evidence-Based

Mental Health

Issue one: Feb 1998

Publication: Quarterly

SUBSCRIPTION RATES:

Institutional:

Worldwide £100, USA only $\$ 160$

Personal:

Worldwide £60, USA only \$96

* Society Members:

Worldwide $\{45$, USA only $\$ 72$

"Applies to members of the Royal College of Psychiotry, The Royal College of Nursing and the British Psychological Society

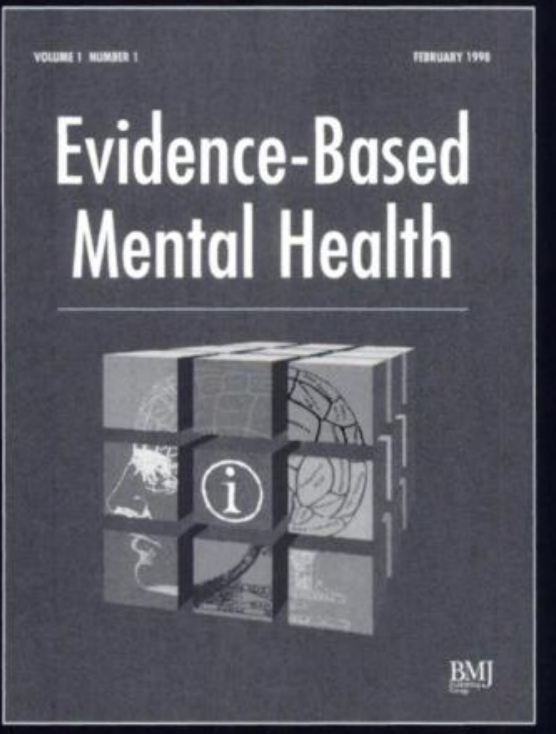

Evidence-Based Mental Health will:

- keep the clinician up-10-date by using scientific criteria to select and abstract the most reliable and important clinically relevant popers from an expanded range of journals

- abstrad promising predinicol studies to keep the specialist informed about current developments

- cover developments in diagnosis, therapy, harm, prognosis, economic evaluation, quality improvement, causation

- provide occompanying commentaries by experienced dinicians to facilitate the integration of research and dinician experience

- provide educational and theoretical articles on development in evidence-based practice, particularly aspects relevant to the mental heallh clinician

- adopt o mulidisciplinary approach to mental health

Evidence-Based Mental Health will be essential reading for clinicians from all disciplines, managers and policy makers

Evidence-Based Mental Health ISSN: 13620347 Publication: Quarterly 1998 Subscription rate: Institutional: Worldwide §100, (USA only S160)

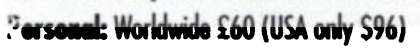

"Society Meabers: Wortwide \{45, (USA only S72)

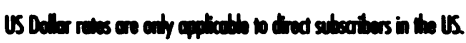

$\square$ Pleose send me o free somple copy

$\square$ Enter my subscription Stort dote:

$\square$ I endose a cheque for $\mathrm{E} / \mathrm{S}$ (poydatb to RMV) Debit my Credit Cord: $\square$ MosterCard $\square$ Viso $\square$ Amex $\square$ Delto $\square$ Switch Switch lssue number

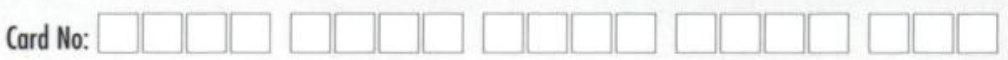

Expiry Date: Signature

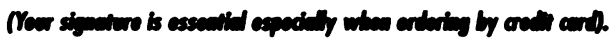

Cordholders Mome:

Speciality/Position.

Cordholders Address:

Post Code

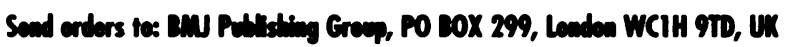

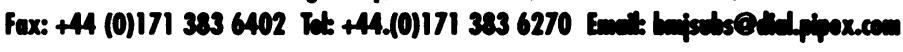

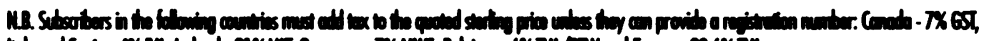

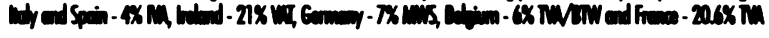




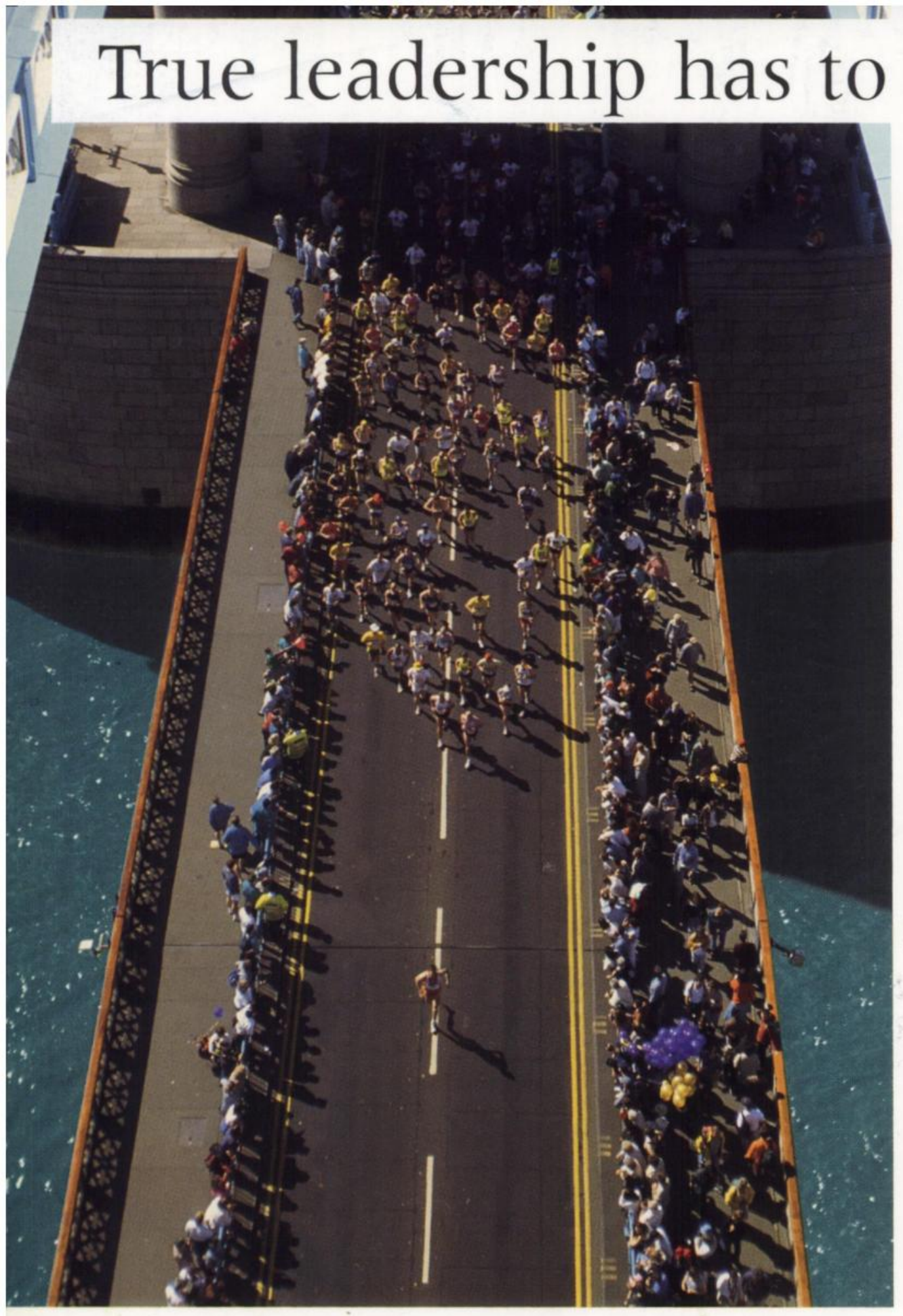

\section{ASSOCIATED ANXIETY}

Prozac has a proven record of efficacy in depression, ${ }^{1,2,3}$ with a confirmed indication in depression with or without associated anxiety symptoms. ${ }^{4}$

A possible reason why Prozac has earned its status around the world.

\section{PR=7AC fluoxetine}

The World's No.1 prescribed antidepressant brand. ${ }^{1}$

'PROZAC' ABBREVIATED PRESCRIBING

INFORMATION (FLUOXETINE HYDROCHLORIDE)

Presentation Capsules containing 20mg or $60 \mathrm{mg}$ fluoxetine, as the hydrochloride. Liquid containing $20 \mathrm{mg}$ fluoxetine, as the hydrochloride. per $5 \mathrm{ml}$ syrup. USEs Depression:

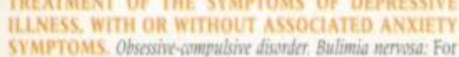
the reduction of binge-eating and purging activity. Dosage and Administration (For full information, see data sheet.) For oral

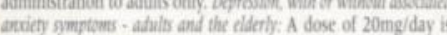
recommended. Otserive-emmulbive tisonter 20me/day $60 \mathrm{mg} / \mathrm{day}$. A dose of $20 \mathrm{mg} / \mathrm{day}$ is recommended as the initial dose. Bulimia - adults and the eliderly; A dose of $60 \mathrm{mg} /$ day is recommended. Because of the long elimination halt-live of the parent drug ( $1-3$ days afier acute administration; may be prolonged to 4-6 days after chronic administration) and its major metabolite (averase 93 davs), active drug substance will persist in the body for several weeks after dosing is stopped. The copsule and liquid dosage forms ate bioequivalent. Orifirot: Nor contra-indications and Precautions sections. Contra. indications Hypersensitivify to fluoxetine. Prozac should no be administered to patients with severe renal failure (GF) <10mimin). Usage in nursing mothers: Promac should not be cast 14 davs should elanse between ofiscontinuation of ath //doi,org/10.1192/S0007125000260261/Publishe
Initiation of therapy with an MAOL. Serious somerimes fatal readions fincluding hyperthermia, rigidity, myodonus, utonomic instability and mental status changes that indude extreme agitation. progressing to delirium and coma) have beer reported with concomitant use or when fluoxetine had been fecently discontinued and an MAOI started. Some cases presented with features resembling neuroleptic malignant syndrome. Warnings Rash and allergic reactions: Angioneurotic oedema, urticaria and other alletgic reactions have been reported. Upon appearance of rash, of of other allergic

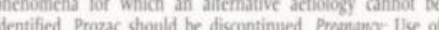
Prozac should be avoided unless there is ne saler aliemative Precautions Prozac should be discontinued in any patient who develops seizures. Pronac should be avoided in patients with unstable epilepsy patients with controlled epilepy sould be carfully moniosed. There bave heen rare rports of prolonger seinures in patients on fluoxetine receiving ECT treatment. A lower dose of Prozac, ce, alternate day dosine is recommended in patients with significant hepatic dvsfunction or mild to failure (GFR 10-50ml/min). Caution is advisable when Prozac is used in patients with acute cardiac disease Prozac may cause weight loss which moy be undesirable iti alter slycaemic control There hare beco repors of ahnorma bleefing in several patients, bur causal triationship to luoxertine and dinical importance are undear. Drue interactivers Increased (with ithium toxicity) of decteased lithium levely Berame by Cambridge University Press monitored cyochiome P4 500106 isoenzyme sstem, ennemitant therapy with othet drugs also metabolised ty this sweem, and which have a nartow therapeutic index (ez carbumazepine, tricydic antidepressants), should be initiated at or adjusted to the lo end of their dose range. Greater than 2-fold increases of previously stable plasma levels of cycic antidepressants have been observed when Prozac has been administered in combination. Agitation, restlessness and gastro-intestinal symptoms have been reponted in a small number of patients reteving liuoxetine in combination with tryptophan. Patienis on stable phenytoin doses have developed elevated plastiva

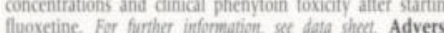
Effects Ashenia frect nausea, diartheea dry mounh, aneetie oss dyspepsia vomiting parely abnormal IFFs, headacte,

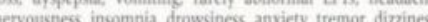
Gatigue, decreased libido, seizures, hvpomania or mania. dvckinesia. movement disorders neuroleptic malienant sndtome-like events, pharnngitis dysonoea, pulmonary evepts finduding inflammatory nroceves and/or fifrosis, rash urticaria vasculitis, excessive sweating, arthralgia, myalgia, serum sickness, anaphylactoid reactions, hair loss, sexual oystumation. The fothowing have been teported in assocation

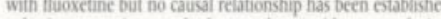
aplastic anaemia, cerebral vasculat accident, confusion. haemorthase, hyperprolactinarmia. immune-related baemolvic anaemia, pancreatitis pancyopenia suicidal ideation. thrombocynopenia. thrombocyropenic purpur
Hrponarnemis induding scrum sodium helow $110 \mathrm{mmol}$ (6) has been rately reponted. This anoears to he reversible upon discontinuation. Overdosage on the evidence available fluoxetine has a wide margin of salety in overdose. Since

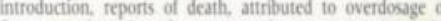
fluoxetine alone, have been extremely rare. One patient who reportedly took $3000 \mathrm{mg}$ of fluoxetine experienced 2 grand mal seizures that remitted spontancously, Legal Category POM Product Licence Numbers 0006/0195 0006/0198 0006/0272 Basic NHS Cost 620.77 per pack of 30 capsules (20mg). E67.85 per pack of 98 capsules (20mig). Review October 1996. Full Prescribing Information is Available From Dista Products Limited, Dextra Coun. Chapel Hill, Basingsoke, Hampshite, RG21 55Y. Telephone: Basingstoke (01256) 52011

Relerences:L. Data on filc, Dista Products LId. 2. Tignol J.J J Ciü

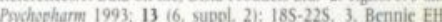
Mullin JM Martindale II J C in Prychiatry 1995; 56 : 229-237. 4. Prozac Data Sheet 24M

Date of preparation: May 1997 PZ906

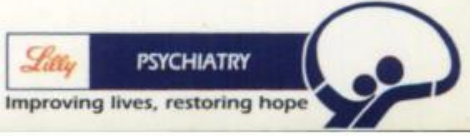

